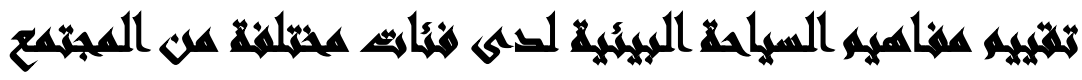 [1r]
}

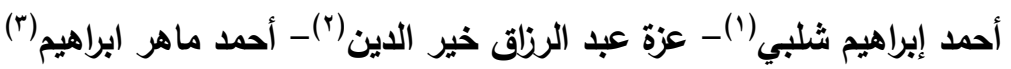

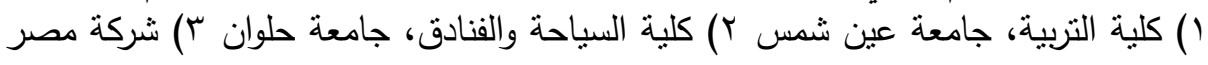
للطيران للسياحة (الكرنك) جاتكة

\section{المستخلئ}

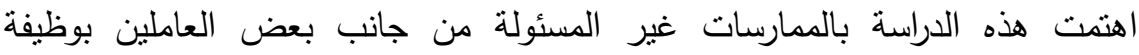

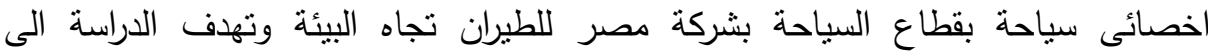

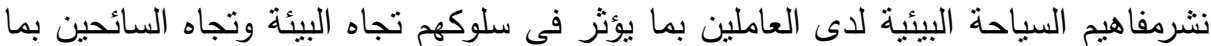

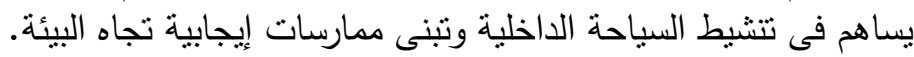

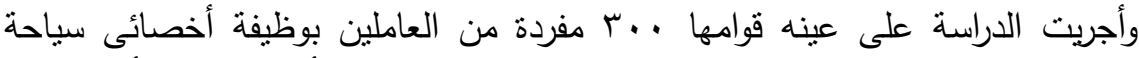
واستخدم الباحثون المنهج الوصفى التحليلى وادوات التقييم ممنلة فى أداة إستبانة لرأى الخبراء

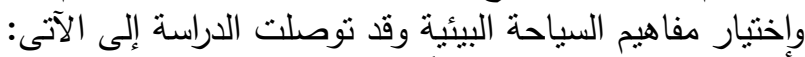

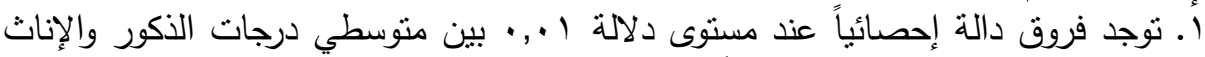

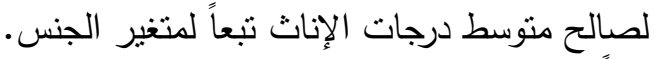

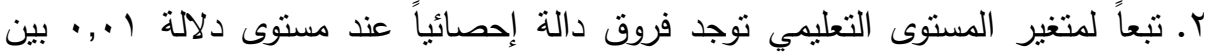

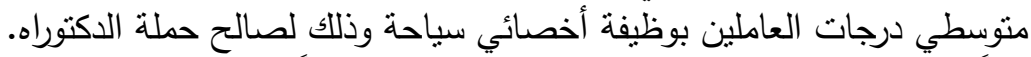

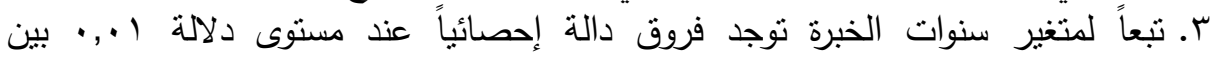

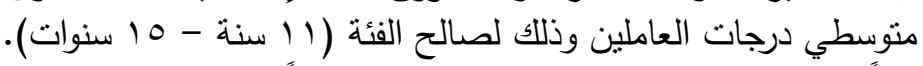

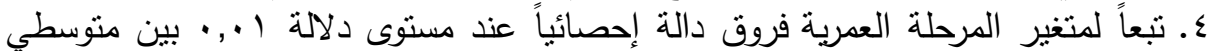

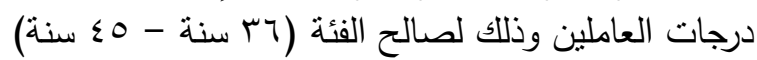
وقد أوصت الدراسة بعقد دورات تدريبية منتوعة للتثقيف بالمفاهيم السية السياحية البيئية وتتفيذ

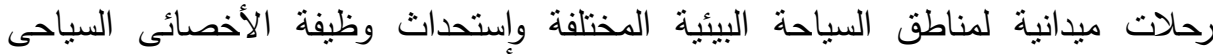
بالمدارس بمراحلها المختلفة، كذللك إنتاج برامج سياحية بيئية على مستوى جيد من الفاعلية

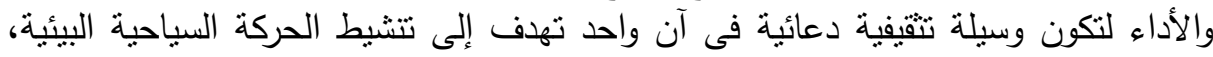

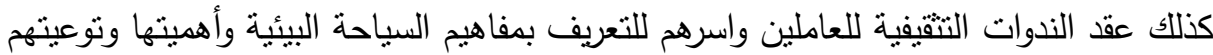

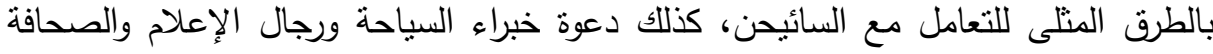
للتعرف على المنتج السياحى البيئي 


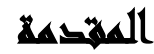

السياحة شأنها شأن كل الأنثطة البثرية تتأثر بملامح البيئة الطبيعية المحيطة والتى

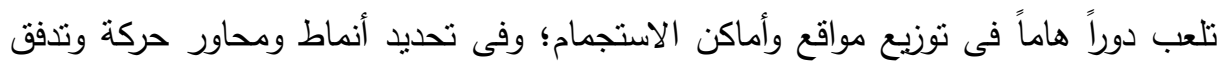

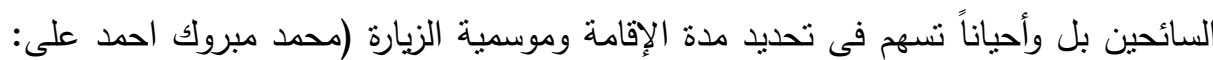

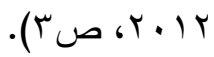

وبالتالى فإن البيئة تهيىء ملامح يبحث عنها السائحون ويحتاجون إليها لذلك يقطعون

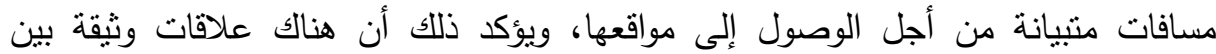

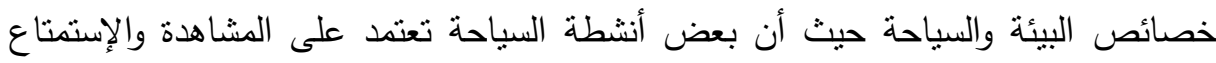

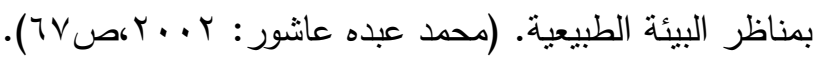
وقد ترتب على التنافس فى جذب السائحين إلى الدقاصد السياحية الدولية العديد من الهشكلات البيئية التى اثرت سلباً على المقومات السياحية، مما إستلزم الإتجاه نحو حماية

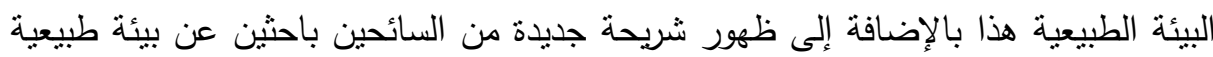

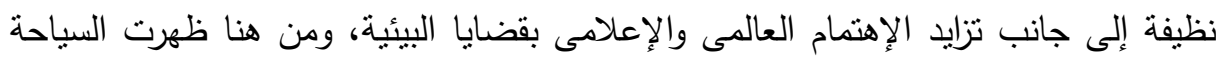
البيئية والسياحة المستدامة وغيرها من الأنماط السياحية التى تهلف إلى إرضاء الإناء السائحين وإثباع رغباتهم من ناحية وحماية البيئة المحلية والمجتمع المحلى من ناحية أخرى (رانيا عبد البداه

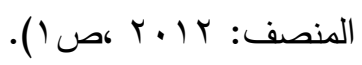

وتمتل السياحة البيئية أحد أهم أنواع السياحة إن لم تكن أهمها على وجه الإطلاق ليس

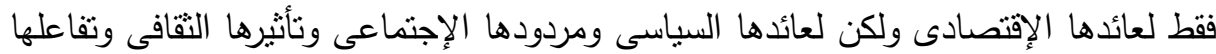

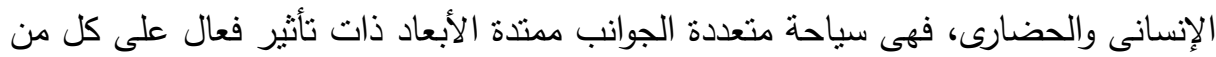

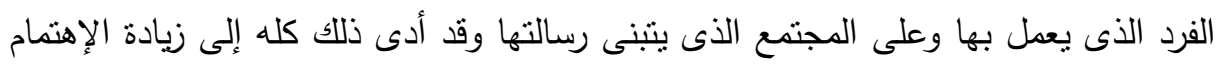

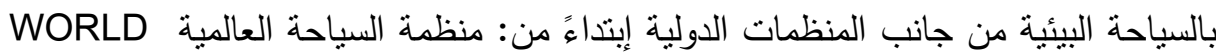
.TOURISM ORGANIZATION

TRAVEL AND TOURISM WORLD ومجلس السفر والسياحة العالمية ومجلس الأرض THE COUNCIL 
المنظمات الحكومية، والمنظمات الجماهيرية غير الحكومية المهتمة بالسياحة والبيئة ويعتبر مصطلح السياحة البيئية من المصطلحات الحديثة نسبياً؛ حيث ظهر منذ مطلع الثمانينيات من

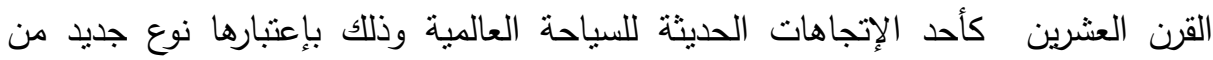
النشاط السياحى الصديق للبيئة الذي يمارسه الإنسان. وأول من أطلق مصطلح السياحة البانية البيأئية هو المعماري المكسيكي وخبير الاتحاد العالمي لصون الطبيعة "هكتور (Eco-Tourism) سباللوس لاسكوراين"، وكان ذلك في عام بهو ام. ويرى سيباللوس لاسكورين أن السياحة البيئية: هي السياحة التي تقتضي السفر إلى المناطق الطبيعية المستقرة Undisturbed نسبياً

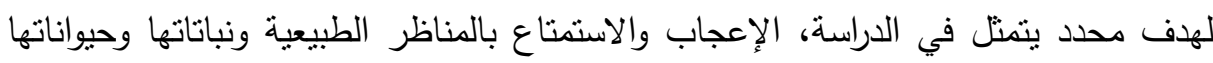

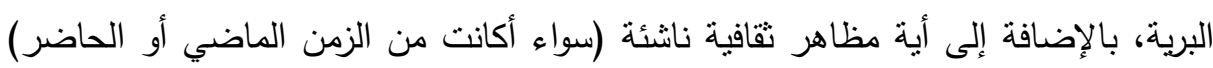

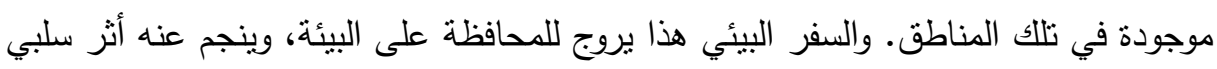

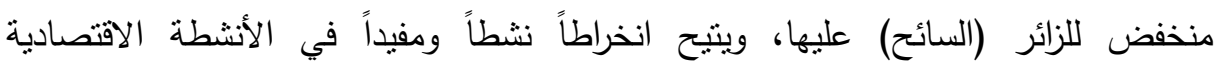

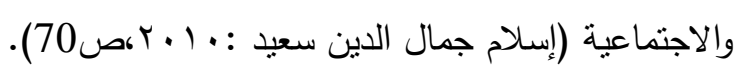

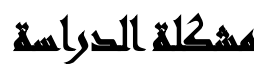

شعر الباحثون بمشكلة البحث الحالى بمركز إتصالات مصر للطيران للسياحة (الكرنك)

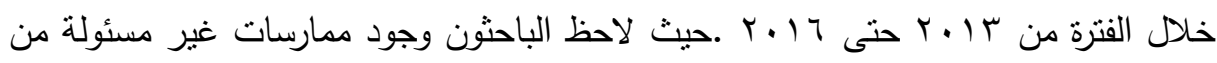
جانب بعض العاملين بوظيفة اخصائى سياحة بقطاع السياحة بشركة مصر للطيران تجاه البيئة.

وقد دعم شعور الباحثون بمشكلة البحث الدراسة الإستطلاعية التى تم إجراؤها على مجموعة من العاملين بوظيفة أخصائى سياحة بشركة مصر للطيران للسياحة (الكرنك) بقائمة

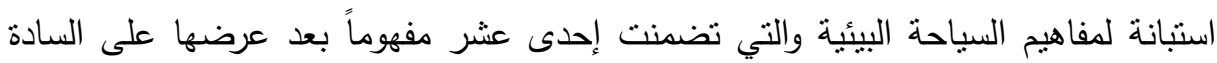
المحكمين والتى أثنارت إلى قصور مفاهيم السياحة البيئية بنسبة ( ع من إختلاف المسنتوى التعليمى وسنوات الخبرة والجنس ومن هنا برزت الحاجة إلى هذه الدراسة فى أن تقييم مفاهيم السياحة البيئية قد يعد وسيلة هامة فى القيام بممارسات إيجابية نحو البيئة وأثر ذلك فى سلوكهم مع السائحين. 


\section{أسئلغالهمهش}

ا. ما المفاهيم السياحية البيئية التى يجب أن يلم بها العاملين بوظيفة أخصائى سياحة من

العاملين بقطاع السياحة من وجهة نظر الخبراء فى مجالات السياحة والتربية البيئية؟ r. ما العلاقة بين مستوى مفاهيم السياحة البيئية لدى العاملين بوظيفة أخصائى سياحة

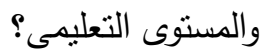

r. ما العلاقة بين مستوى مفاهيم السياحة البيئية لاى العاملين بوظيفة أخصائى سياحة

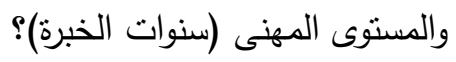

ع. ما العلاقة بين مستوى مفاهيم السياحة البيئية لدى العاملين بوظيفة أخصائى سياحة

$$
\text { والعمر؟ }
$$

ه. ما العلاقة بين مستوى مفاهيم السباحة البيئية لدى العاملين بوظيفة أخصائى سباحة

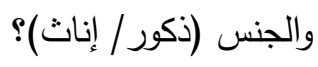

\section{أهمية المهمي}

تكمن أهية الدراسة إلى أنها قد تقيد الفئات التالية: '. العاملين بالسياحة على سبيل المثال (العاملين بشركة مصر للطيران للسياحة (الكرنك): إدراك العاملين بالسياحة للمفاهيم البيئية السياحية يؤثر في سلوكهم تجاه البيئة تجاه

$$
\text { السائحين وتنبي للممارسات الإيجابية تجاه البيئة . }
$$

r. يفيا القائمين على وضع البرامج الدراسية: بالنسبة لشعبة الإرشاد السياحى بكليات السياحة والفنادق أو قسم الإرشاد السياحى بكليات أداب للإستفادة منه فى تضمين المقررات الدراسية للمفاهيم المتعلقة بالسياحة البيئية.

\section{أهماهنم التراسما}

هدف الدراسة هو تقييم مفاهيم السياحة البيئية لدى فئات مختلفة من المجتمع بما يساهم

في تتشيط السياحة الداخلية وتبني ممارسات إيجابية تجاه البيئة. 


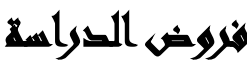

• توجد فروق دالة إحصائياً عند مستوى دلالة ا .,. ب بين منوسطي درجات الذكور والإناث

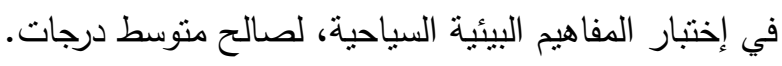

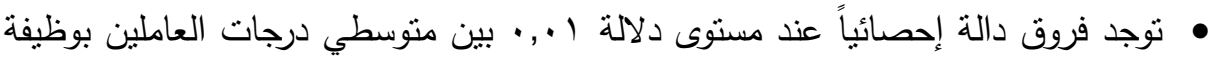

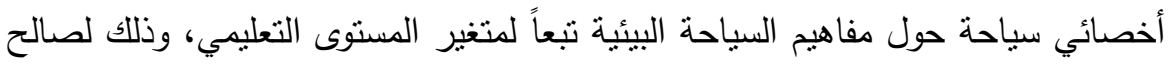

$$
\text { المؤهل الأعلى (حملة الدكتوراه). }
$$

• توجد فروق دالة إحصائباً عند مستوى دلالة ا •, • بين متوسطي درجات العاملين بوظيفة

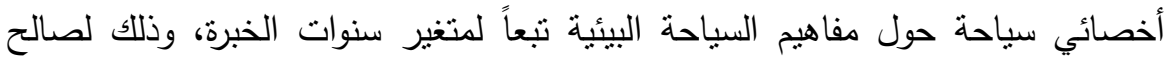

$$
\text { السنوات الأعلى خبرة وهم الفئة (1) سنة - } 110 \text { - } 1 \text { سنوات). }
$$

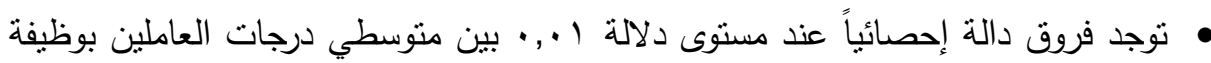

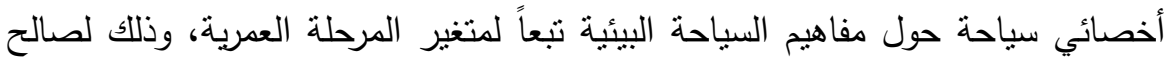

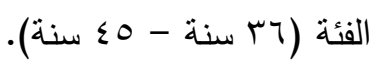

\section{مهاهيه الصراسمة}

- السياحة الإيكولوجية ( يسرى دعبس، (. . . ) هى السفر إلى المناطق الطبيعية البكر

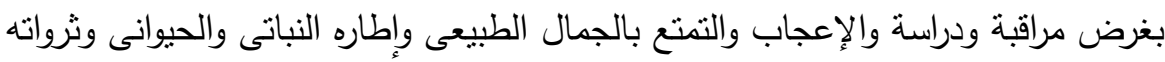

$$
\text { الطبيعية التى لم تخربها الحياة المدنية. }
$$

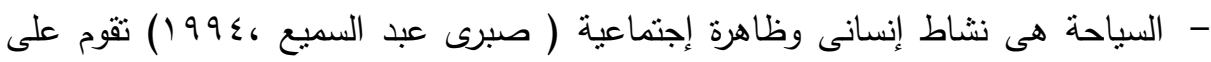

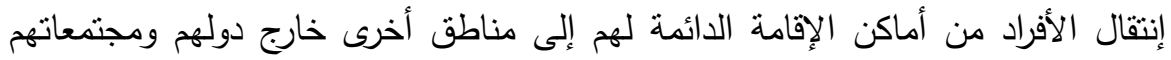
لفترات مؤقتة لاتقل عن ع باعة ولاتزيد عن عام كامل لغرض من أغراض السياحة

$$
\text { المعروفة }
$$

- السائح البيئى هو السائح المسؤول الذي يحمي ويحافظ على الحياة الفطرية ومواطنها

الطبيعية ويحترم عادات وثقافات المنطقة المراد زيارتها (Colvin, 1991) 


\section{لم=وض القراسما}

المجال المكانى: أجريت الدراسة على العاملين بقاع السياحة (الكرنك ) بشركة مصر • للطيران

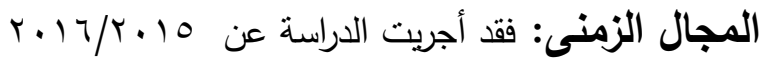
المجال البشرى: العاملين بوظيفة أخصائى سياحة.

\section{هنهمج الدواسمة}

اعتمدت الدارسة الحالية على المنهج الوصفى التحليلى فى دراسة واقع مفاهيم السياحة البيئية وتقصى أراء الخبراء فى المفاهيم التى يجب أن يلم بها العاملين بقطاع السياحة.

\section{إجزاءايه الدوالمة}

- - إعداد قائمة المفاهيم السياحية البيئية. - تحديد الهدف من وضع قائمة الدفاهيم البيئية السياحية ونوعها وتمنل هدف الأستبانة هو معرفة ما المفاهيم السياحية البيئية التى يجب ان يلم بها العاملين بوظيقة أخصائى سياحة

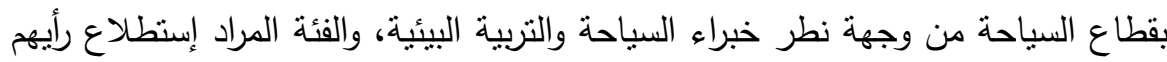
هم العاملين بوظيفة أخصائى سياحة (ذكور - إناث) بقطاع السياحة، وتحدد نوع الإستبانة في كونها إستبانة تحوى نوعى الأسئلة المفتوحة والمقيدة. - إجراءات إعداد القائمة والتى تضمنت إطلاع الباحث على الأدبيات والدراسات السابقة مثل

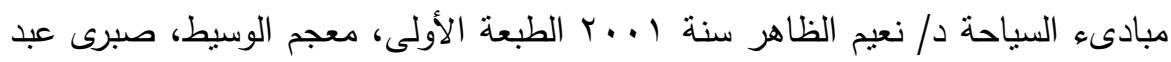

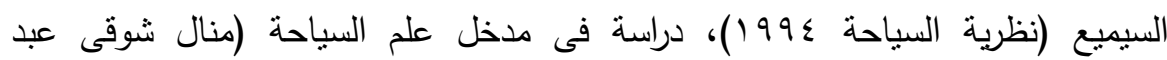

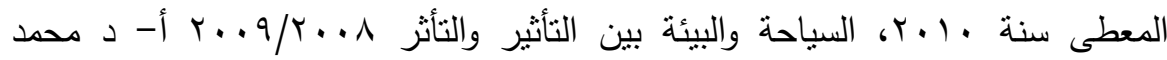
الصبرفى الفصل السابع السياحة البيئية، كتاب السياحة (مفهومها وانماطها وانواعها أ - د دينه

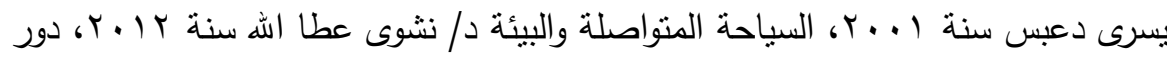
البينية الإندماجية فى تتشيط حركة السياحة الدولية الوافدة إلى مصر د د مصطفى صبحى دئه 
ابو النيل، عبد الرحمن عبد الفتاح واخرون (السياحة البيئية ) - مطابع جامعة المنوفية،

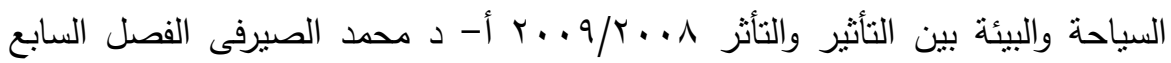
السياحة البيئية - مرجع سبق ذكره-، الجمعية الدولية للسياحة البيئية والمجلس العالمى

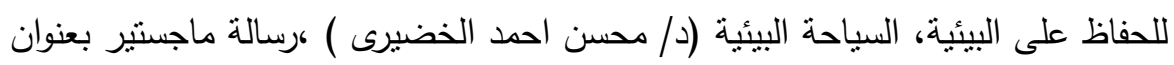

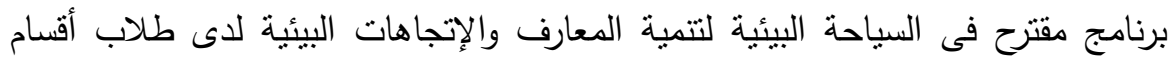
السياحة بمعاهد التعليم العالى (الباحثة - مريم محمود مصطفى 9 . . ب )، رسالة دكتوراه

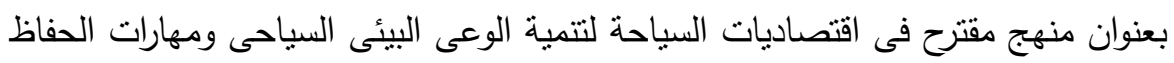

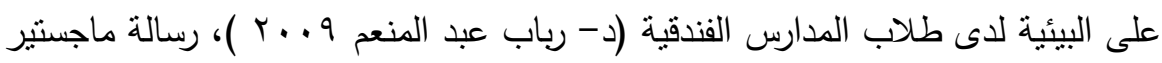

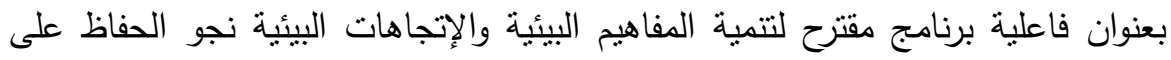
بيئة البحر الأحمر لاى طلاب المرحلة لإعدادية بمحافظة جنوب سيناء (الباحثة - اسماء

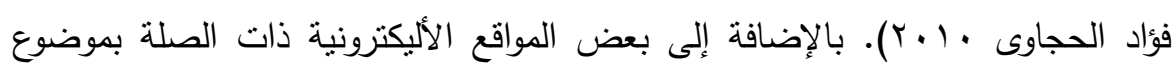
الدراسة والتى نم إدراجها فى قائمة المراجع فى نهاية الدراسة.

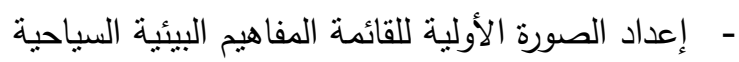

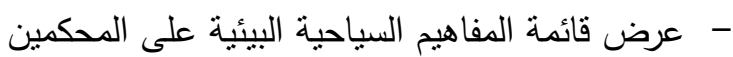
- وضع قائمة المفاهيم السياحية البيئية فى شكلها النهائى (ضبط الإستبانة) والنى إحتوت على إحدى عشر سؤالاً - الصدق Validity: اعتمد الباحث في حساب صدق الدقياس على الصدق المنطقي لـ Logical Validity (صدق المحكمين) -

الأساليب الإحصائية المستخدمة: استخدم الباحث عدداً من الأساليب الإحصائية هي: التكرارات والنسب المئوية. ومعادلة ألفا كرونباك لحساب ثبات الأدوات ومعامل ارتباط بيرسون لحساب ثبات الاتساق الداخلي للمقياس، والتحقق من الفروض واختبار "ت" لمعرفة الفروق بين الذكور والإناث، واختبار تحليل التباين أحادي الاتجاه للكثف عن الفروق طبقاً لسنوات الخبرة والمستوى التعليمي، ومراحل العمر المختلفة. 
وقد أوضحت العديد من الدراسات السابقة:

أهمية تضمين المفاهيم البيئية بمناهج الدراسة ورطها بالقضايا والمشكلات البيئية حيث

إن الهدف العام للتربية البيئية هو إعداد الفرد الإيجابى نحو حمايتها ولديه القدرة على إتخاذ القرارت الصحيحة التى تؤدى إلى الحفاظ على التوازن البيئى وتحمل المسئولية والمهارات العلمية التى تمكنه من العمل على حماية البيئة وحل مشكلاتها (صلاح عبد المحسن،

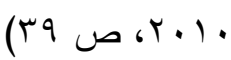

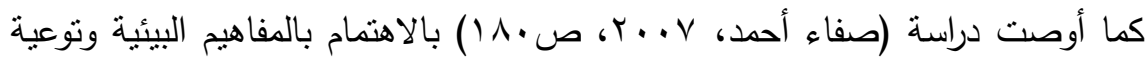
الأسرة بأهمية التربية لبيئية وغرس المفاهيم البيئية وفى ضوء ذلك أجريت العديد من الدراسات

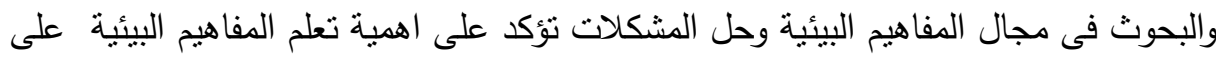
البيئة والمساهمة الإيجابية فى حل المشكلات البيئية ومن هذه الدراسات دراسة (اسماء فؤاد،

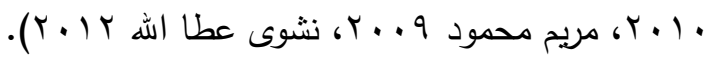

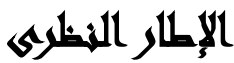

$$
\begin{aligned}
& \text { يتتاول بالعرض المفاهيم الرئيسية للدراسة وهي: }
\end{aligned}
$$

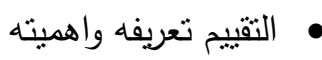

$$
\begin{aligned}
& \text { • المفاهيم البيئية (التعريف - السمات - اهمية تعلم المفاهيم البيئية ) } \\
& \text { • (- مفاهيم السياحية }
\end{aligned}
$$

• المفاهيم السياحية البيئية (نشأة السياحة البيئية - التعريف - نمو السياحة البيئية )

$$
\text { • • ن •بذة عن نشأة الطبران فى جمهورية مصر العربية. }
$$

• فكلمة التقيب ليس لها أصل إنتقاقى فى اللغة العربية لكنها ترجمة

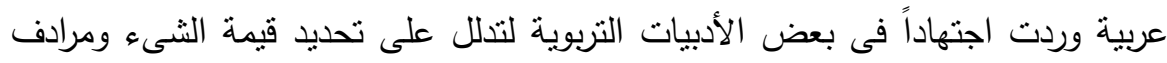
هذا المصطلح فى اللغة العربية هو التقدير • وفى هذا الإطار يشير (زاهر احمد، 1997

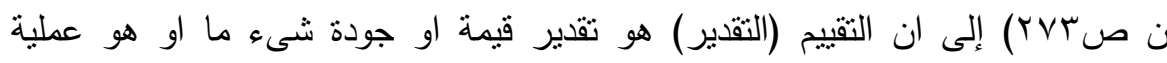
تشخيص مشاكل الفرد . 


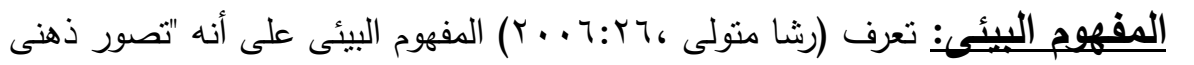
ينتج من تجميع عدد من الأفكار والمعانى ذات الخصائص المشتركة أو يقرر بعض أنواع العلاقات بين عدة مواقف أو حقائق تتعلق بالبيئة بحيث يمكن الطفل من التعرف عليها

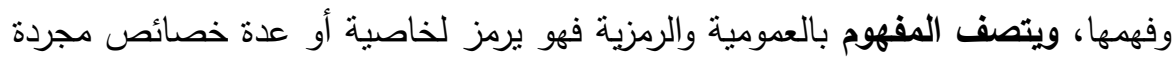

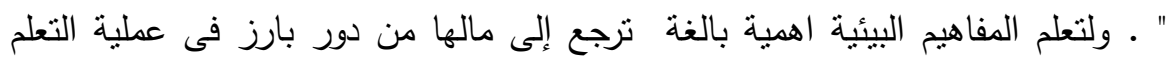

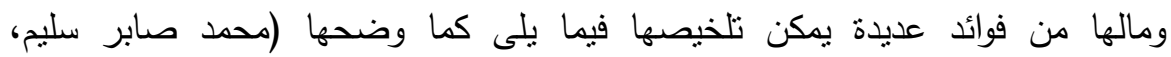

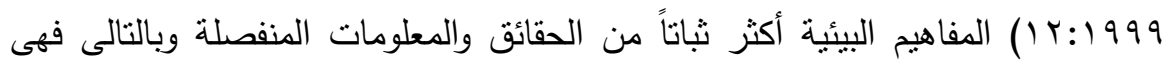

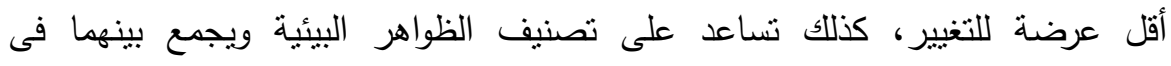
مجموعات مما يقلل من تعقد البيئة ويسهل من دراسة مكوناتها وظواهرها .كما تسمح

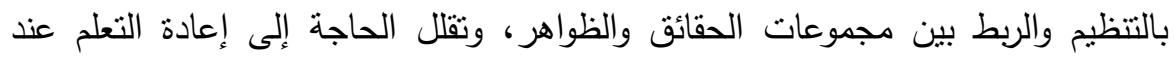

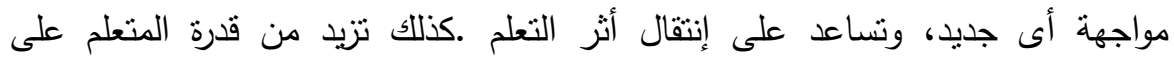

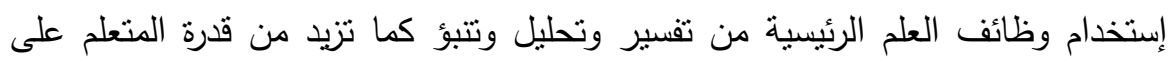
إستخدام المعلومات فى مواقف حل المشكلات .

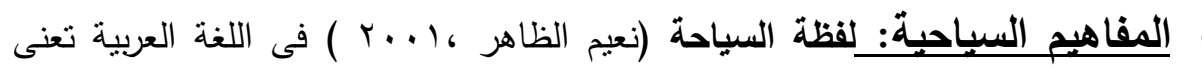

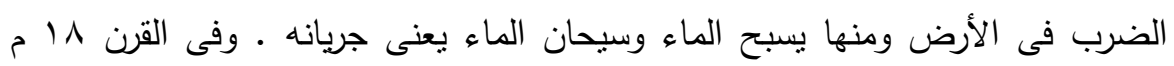
تطور إستخدام مصطلح الرحلة الكبيرة ثم إنتقل المصطلح إلى إنجلترا حيث إستخدم للتعبير

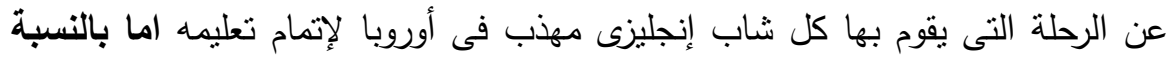

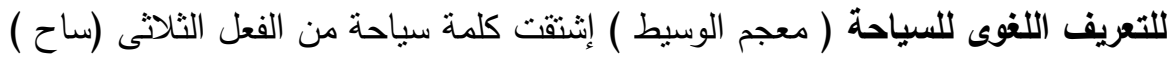
وهو يدل على جملة من المعانى السيولة والجريان - الذهاب والسير - التعبد والترهب مداومة الصوم- الرجوع من مكان إلى مكان. واللسياحة فى الإصطلاح هى التتقل من بلد

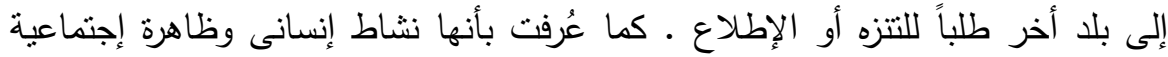

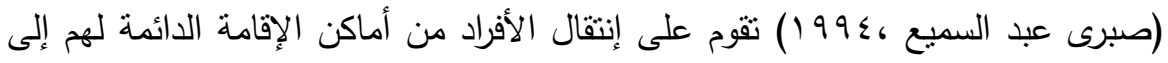

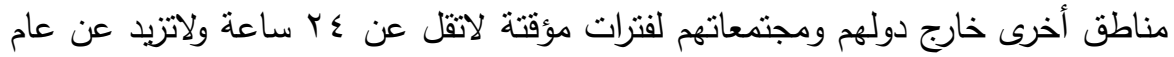

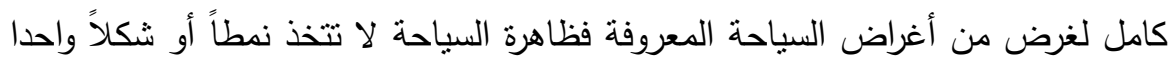


وانما هى اصطلاح يمثل نوعاً من النشاط الأنسانى يضم عدة أنثكال وانماط للسفر والإقامة فى الدولة او المنطقة المقصودة تبعاً لدوافع متعددة هى أساس فعل الأنتقال وبالتالى فالسياحة كظاهرة تتنوع وتتخذ عدة انماط تبعاً لما يلى الإنى عدد الأشخاص المسافرين: مابين السياحة الفردية وسياحة جماعية طبقاً للهدف من الرحلة او الدافع للسفر (السياحة الترفيهية - السياحة الثقافية - - السياحة العلاجية- السياحة الدينية - السياحة الرياضية - سياحة المؤتمرات ...

المفاهيم السياحية البيئية:

نشأت السياحة البيئية منذ قديم الزمان حيث جذبت الطبيعة المستكثفين والمغامرين

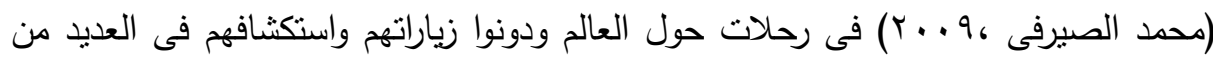
الكتب والمخطوطات وكان لهم أكبر الأثر على إكتشاف دول مجهولة بل قارات بأكملها .

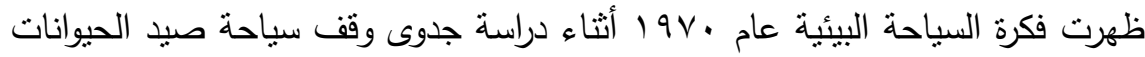

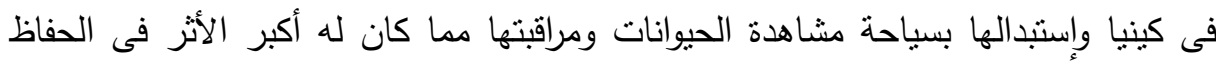
على الحياة البرية وتوفير الموارد المالية التى أستغلت فى إقامة المحميات الطبيعية وتوفير

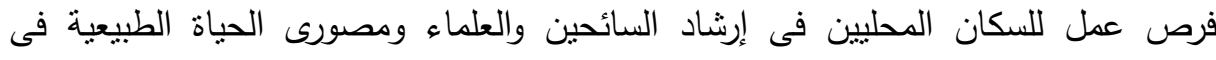
eco-) المناطق النائية وفى أوائل الثمانينات من القرن العشرين ظهر مصطلح السياحة البيئية (tourism

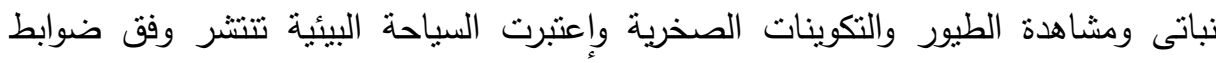
للحفاظ على الموارد البييئية وتتمية المجتمعات المحلية حيث شعارها لاتترك شيئًاً خلفك ولاتأخذ

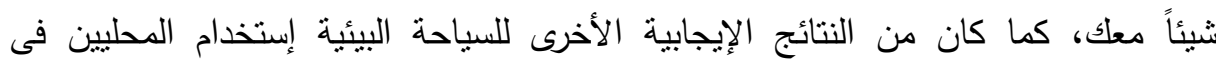
مشاركة السائحين والعلماء فى المحافظة على البيئة والعمل فى هذه المناطق مما كان له أكبر الإني الأثز فى الحفاظ على البيئة ورفع مستوى معيشتهم •وفى عام •99 ام تم إنثاء الجمعية

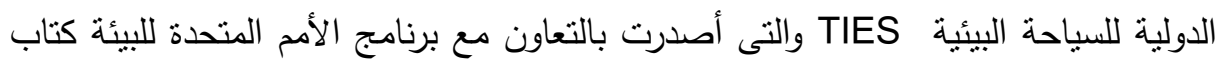

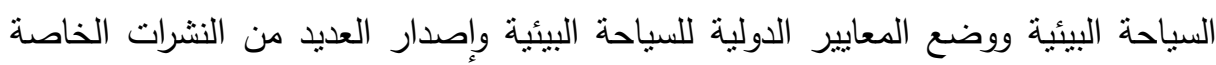
بها ونظراً لأهمية السياحة البيئية فى الحفاظ على التراث الحضارى والموارد الطبيعية التى هى لـى لهئه 
أساس الحركة السياحية كما أنها ترفع مستوى معيشة السكان المحليين لذلك أعلنت منظمة

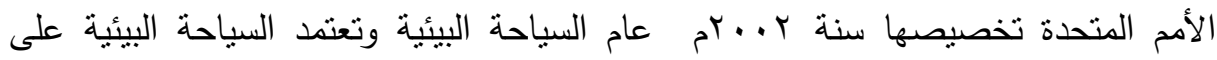
التريض فى الجبال ومراقبة الطيور وتأمل الطبيعة وسفارى التصوير والغابات والأنهار والرحلات البحرية .

وقد برز مفهوم السياحة البيئية منذ عدة سنوات كإختيار عملى للحفاظ فى أن واحد على

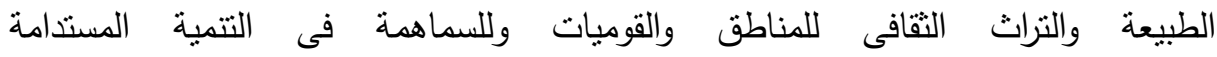
SUSTANABLE DEVELOPMENT . مصطلح SUSTAINABILITY على النحو كالتالى: سد إحتياجات الحاضر بدون إضعاف إمكانيات الإجيال المقبلة من سد إحتياجاتهم وقد

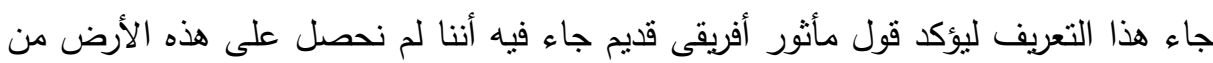

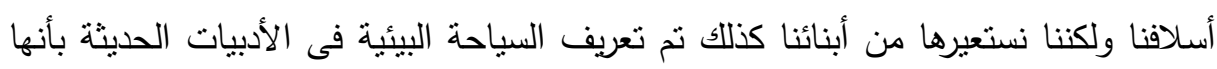

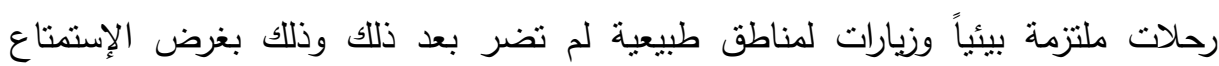
والدراسة وتأمل الطبيعة وملامحها الثقافية. طبقاً لتعريف الجمعية الدولية للسياحة البيئية , 1991 TIES وتعريف المجلس العالمى للحفاظ على البيئة IYCN سنة 1997 والخصائص التى حددتها منظمة السياحة

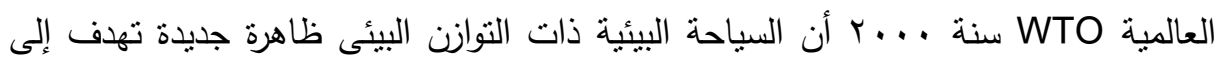

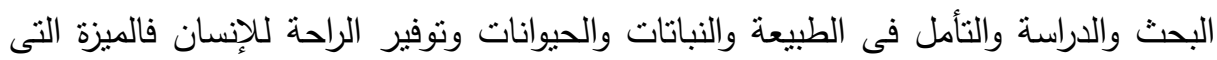

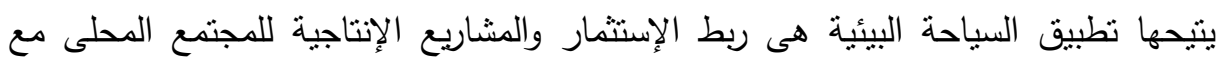
حماية البيئة والتتوع الحيوى والثقافى وفق معادلة تتموية واحدة وذللك عن طريق إعداد برامج

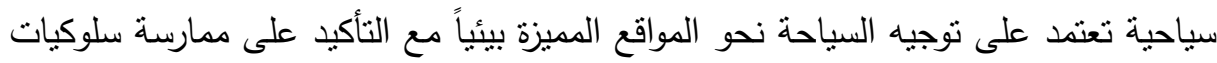

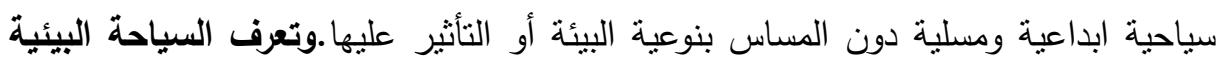

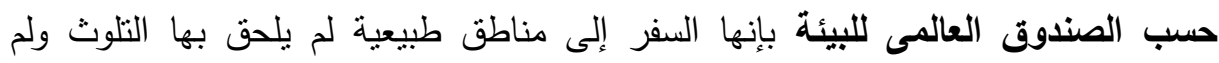

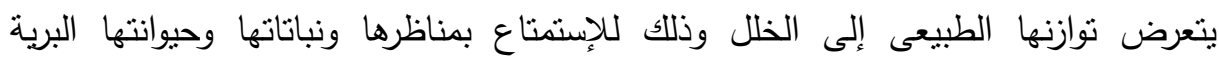

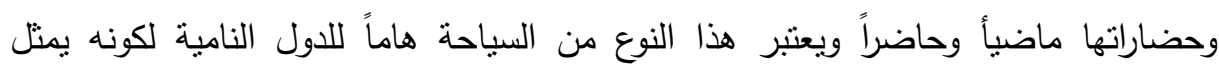


مصدراً للاخل إضافة إلى دوره فى الحفاظ على البيئة وترشيح ثقافة وممارسات التتمية

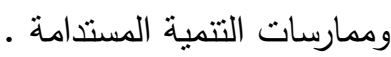

ECO وترى (نشوى عطاله ، Y. T) ويتألف مصطلح السياحة الإيكولوجية TOURISM (ECOLOGY) ودعامة حياتهم.

اما ( يسرى دعبس، (Y. P ) فيرى السياحة الإيكولوجية هى السفر إلى المناطق

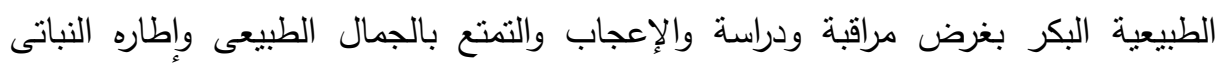
والحيوانى وثرواته الطبيعية التى لم تخربها الحباة المدنية. ومن أكثر التعاريف شيوعاً نعريف CEBALLOS- LASCURAIN فهو يعرفها على لخى انها سياحة إلى مناطق طبيعية ليس بها تلوث أو تغيير وهدفها هو الدراسة والإنتمناع بالمناظر الطبيعية والحيوانات والنباتات واى مظاهر حضارية قائمة (الماضى منها والحاضر ) فى هذه المناطق. ومن واقع بيانات منظمة السياحة العالمية (WTO 1996) فإن الطلب على السياحة البيئية والرحلات الموجهة بيئياً فى حالة صعود ملحوظ لدرجة أنها أصبحت أسرع قطاع ينمو

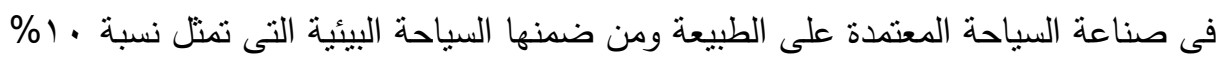
إلى 10 \% من إجمالى إنفاق السياحة العالمية.

تعتبر مصر للطيران من الثركات الرائدة فى العالم وقا اصبحت عند عند تأسيسها فى شهر

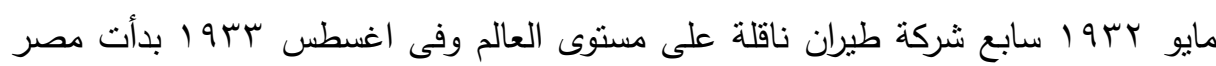
للطيران فى تشغيل عملياتها التجارية بطائرات من طراز سبارتان كروزر تعمل بين بين القاهرة

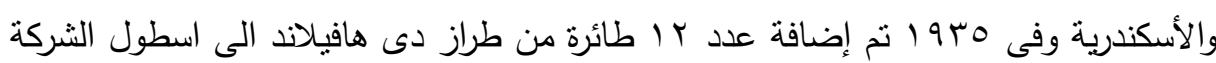

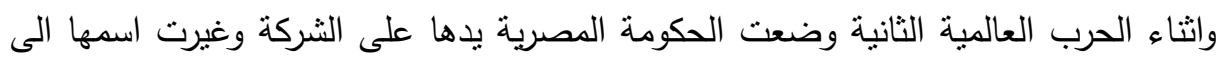
مصر للطيران - مصر ايرلاينز - مصنه 
وفى عام 19 19 نم تغيير اسم الثركة من مصر ايرلاينز الى مصر اير وتم شراء عدد • 1 طائرات من طراز بيتش كرافتر وبذلك اضيفت التكنولوجيا الأمريكية الى الأسطول وفى لئل

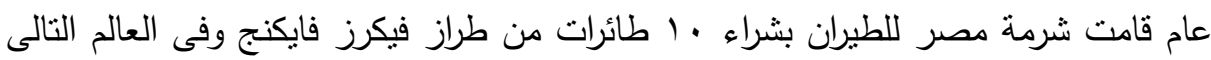

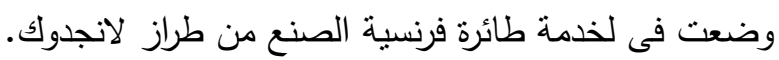

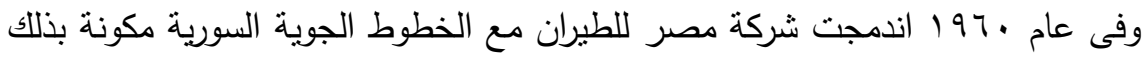
كيانا جديدا باسم شركة الطيران العربية المتحدة وقامت شركة الطيران العربية المتحدة بتعزيز اسطولها بطائرات نفاثة من طراز كوميت ع سيى وبذلك اصبحت اول شركة طيران فى الثرق لثرن الأوسط تستخدم الطائرة النفاثة.

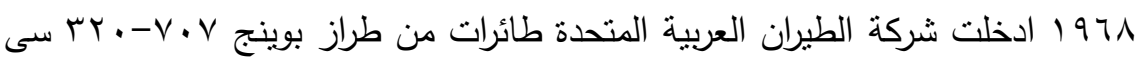
وذلك لتلبية حركة السفر الدولية المتتامية ونتشغيل الخطوط بعيدة المدى . 1979 اصبحت شركة الطبران العربية لمتحدة اول شركة طيران فى الثرق الأوسط تقوم بتشغيل الطائرات من طراز بوينج V. V. V. |9VI انفصلت الخطوط الجوية السورية عن شركة الطيران العربية المتحدة مما ادى الى تغيير وضعها القانونى لتصبح مصر للطيران.

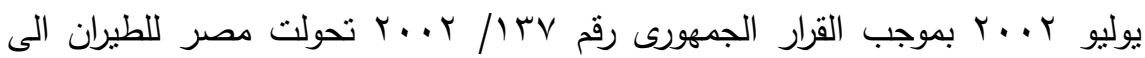
شركة قابضة تتبعها سبع شركات فرعية.

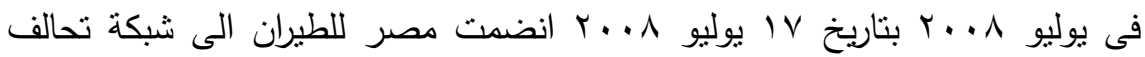

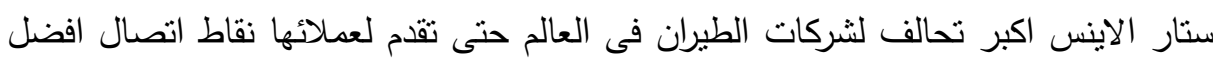
وسفر واكثر راحة وتعتبر عضوية مصر للطيران فى تحالف ستار حدثا فريدا من حيث انها شركة الطيران الوحيدة فى شمال افريقيا والثرق الأوسط التى تعتبر جزءا من هذه وانه الثبكة. وقد تأسس قطاع السياحة (الكرنك) بشركة مصر للطيران عام 1900 كاحد الشركات الثرات

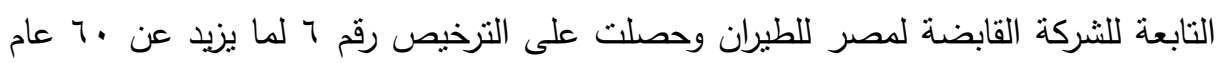

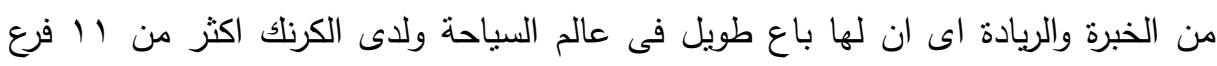

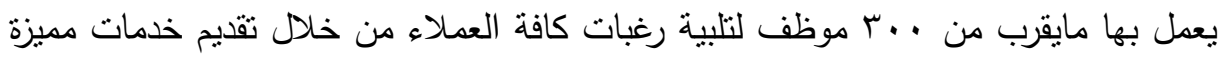


سواء المتعلقة بحجز تذاكر الطيران على اكثر من ·ـ شركة طيران او تقديم برامج سياحية شاملة داخلية وخارجية او تتظيم رحلات الحج والعمرة او تتظيم المعارض والأحداث الخاصنة. مجموعة الدراسة: تكونت مجموعة الدراسة الأساسية من (VY) مفرده من الإناث و و

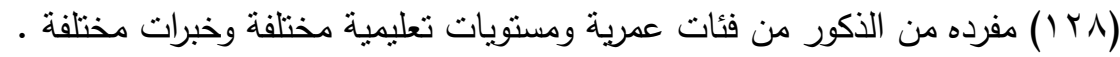

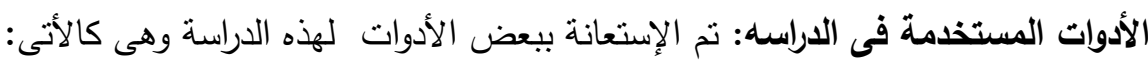
() إعداد قائمة إستنيان الهفاهيم السياحية البيئية ( - كفاءة مقياس المفاهيم البيئية السياحية (الصدق - التبات)

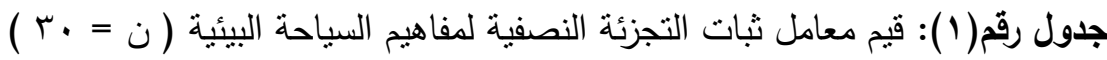

\begin{tabular}{|c|c|c|c|}
\hline مستوى المعنوية & معامل سبيرمان & معامل جتمان & لخواص \\
\hline , , . & $* *, 9 \leq r$ & $* * *, 9 \leq r$ & لمقياس \\
\hline
\end{tabular}

أساليب التحليل والتفسير: اعتمت الدراسة الحالية على الأساليب الإحصائية التالى ذكرها

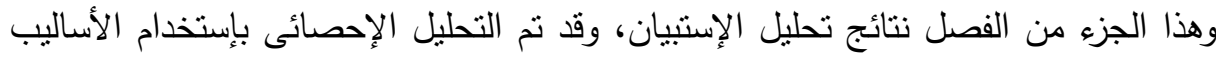

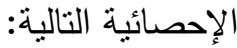
1- التكرارات والنسب المئوية ومعادلة ألفا كرونباك لحساب ثبات الأدوات. r-معامل ارتباط بيرسون لحساب ثنات الاتساق الداخلي للمقياس، والتحقق من الفروض. r-اختبار "ت" لمعرفة الفروق بين الذكور والإناث. ع-اختبار تحليل التباين أحادي الاتجاه للكثف عن الفروف طبناً لسنوات الخبرة والمستوى لـات التعليمي، ومراحل العمر المختلفة.

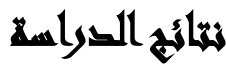

الفرض الأول: " توجد فروق ذات دلالة إحصائية بين العاملين بوظيفة أخصائى سياحة

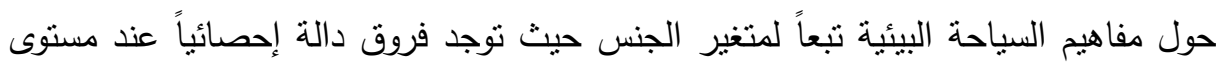
دلالة ا +,. بين متوسطي درجات الذكور والإناث في الدفاهيم البيئية السياحية، لصالح متوسط درجات الإناث وللتحقق من صحة هذا الفرض والكثف عن الفروق بين متوسط 342

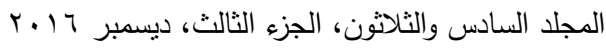


درجات العاملين بوظيفة أخصائي سياحة حول مفاهيم السياحة البيئية تبعاً لمتغير الجنس

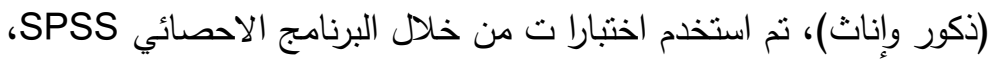
جدول رقم(ץ): الفروق بين متوسط درجات العاملين بوظيفة أخصائي سياحة حول مفاهيم السياحة البيئية تبعاً لمتغير الجنس (ذكور وإناث)

\begin{tabular}{|c|c|c|c|c|c|c|}
\hline مستوي & قيمة & الالحعيارى & الحستوبي & العدد & النوع النوع & الأبعاد \\
\hline \multirow{2}{*}{$\cdot, \cdot}$, & \multirow{2}{*}{7,01} & Y,00YT. & YA, IAVO & IrA & ذ ذكور & \multirow{2}{*}{ المفاهيم البيئية السياحية } \\
\hline & & 1,vvrqr & $r q, \wedge \Gamma) \varepsilon$ & IVT & إناث & \\
\hline
\end{tabular}

توجد فروق دالة إحصائياً عند مستوى دلالة ا ب, • بين منوسطي درجات الذكور والإناث

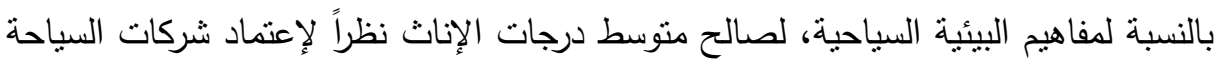

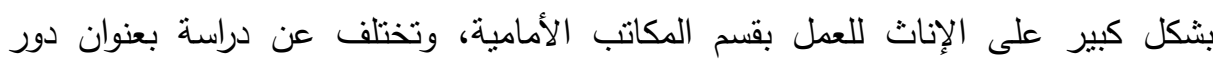
السياحة البيئية فى نتمية المجتمع المحلى - دراسة ميدانية فى محافظة جنوب سيناء للباحثة / نادية أحمد الطيب والتى أثنارت فيها الباحثة ان نسبة الذكور أعلى من نسبة الإناث نظرا لإلتحاق الذكور من أقليم الصعيد على العمل بالمناطق السياحية وقلة عدد الإناث العاملات بمجال السياحة البيئية. الفرض الثانى: توجد فروق ذات دلالة إحصائية بين العاملين بوظيفة أخصائى سياحة حول واقع مفاهيم السياحة البيئية تبعاً لمتغير المستوى النعليمي

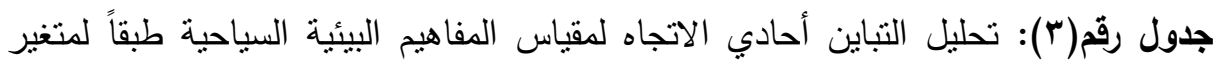

\begin{tabular}{|c|c|c|c|c|c|}
\hline & & & \multicolumn{3}{|c|}{ المستوى التعليمي } \\
\hline الدلالة & قيمة F & متوسط المربعات & درجات الحرية & مجموع المربعات & الخواص \\
\hline \multirow{3}{*}{$\cdot, \cdots$} & \multirow{3}{*}{$0, Y \leqslant \wedge$} & $Y 0,9 \vee \leqslant$ & $\varepsilon$ & $1 . r, \wedge 97$ & بين المجموعات \\
\hline & & $\leq, 9 \leq 9$ & r9o & $1 \leq 7 \cdot, \cdot r \varepsilon$ & داخل المجموعات \\
\hline & & & rq9 & 107r,94. & Total \\
\hline
\end{tabular}


حيث نوجد فروق دالة إحصائياً عند مستوى دلالة ا •, • بين منوسطي درجات العاملين

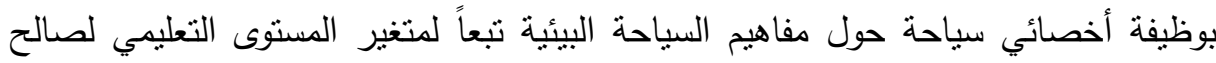

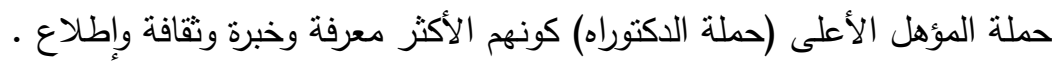
الفرض الثالث: توجد فروق ذات دلالة إحصائية بين العاملين بوظيفة أخصائى سياحة حول واقع مفاهيم السياحة البيئية تبعاً لـتغير سنوات الخبرة". جدول رقم(؛): تحليل التباين أحادي الاتجاه لمقياس المفاهيم البيئية السياحية طبقاً لمتغير سنوات الخبرة

\begin{tabular}{|c|c|c|c|c|c|}
\hline الدالة & قيمة F & متوسط المريعات & درجات الحرية & مجموع المربعات & الخواص \\
\hline \multirow{3}{*}{$\cdot, \cdots$} & \multirow{3}{*}{$0 \leqslant, \lambda r$} & 117,191 & $r$ & $00 \wedge, 0 \vee \leqslant$ & بين المجموعات \\
\hline & & r, rqт & r97 & $1 \cdots 0,107$ & داخل المجموعات \\
\hline & & & rq9 & $107 \pi, 94$. & Total \\
\hline
\end{tabular}

حيث توجد فروق دالة إحصائياً عند مستوى دلالة ا .,. ب. ب وذلك لصالح الفئة (1 (اسنة - 10 الفرض الرابع: " توجد فروق ذات دلالة إحصائية بين العاملين بوظيفة أخصائى سياحة

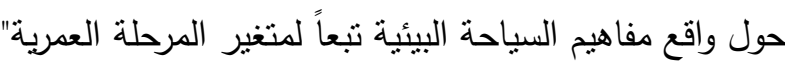
جدول رقم(ه): تحليل التباين أحادي الاتجاه لكقياس المفاهيم البيئية السياحية طبقاً لمتغير

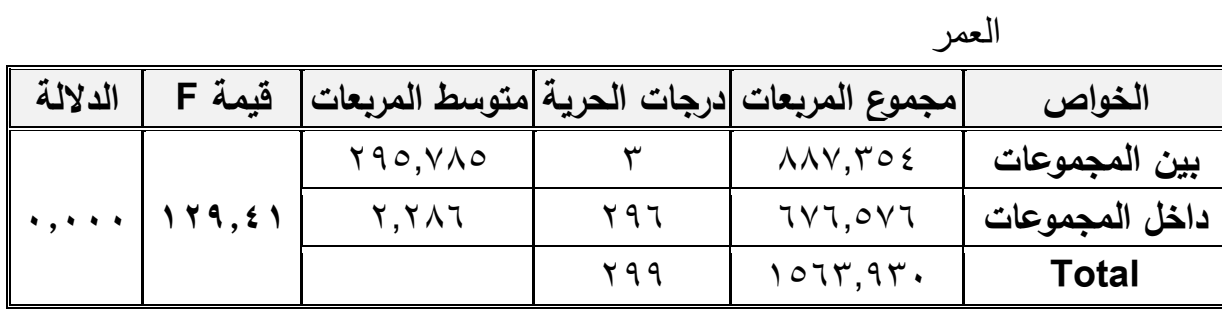
توجد فروق دالة إحصائياً عند مستوى دلالة ا..,· بين متوسطي درجات العاملين

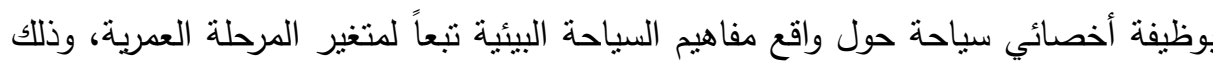

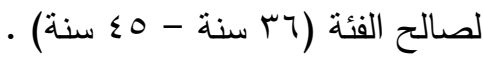




\section{تمشسير نتمائي الصراسمة}

دلت نتائج الدراسة على وجود فروق ذات دلالة إحصائية بين العاملين بوظيفة أخصائى سياحة تبعاً لمتغير الجنس حول المفاهيم البيئية السياحية لصالح منوسط درجات الإناث نظراً

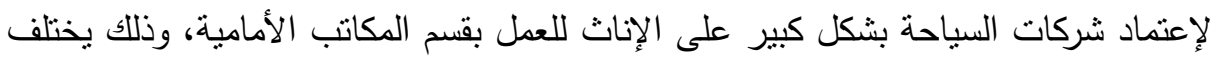
عما توصلت إليه دراسة بعنوان دور السياحة البيئية فى تتمية المجتمع المحلى - دراسة الإنة

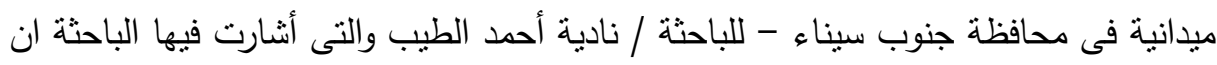

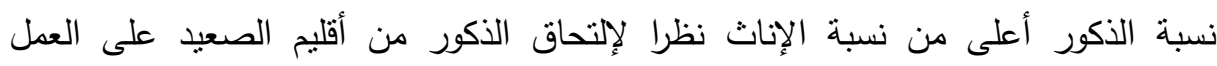
بالمناطق السياحية وقلة عدد الإناث العاملات بمجال السياحة البيأية البية كذلك توجد فروق ذات دلالة إحصائية بين العاملين بوظيفة أخصائى سياحة حول مفاهيم السياحة البيئية تبعاً لمتغير المسنوى التعليمي لصالح حملة المؤهل الأعلى (حملة الدكتوراه)

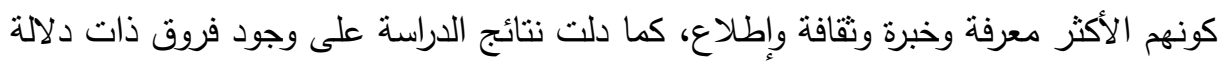

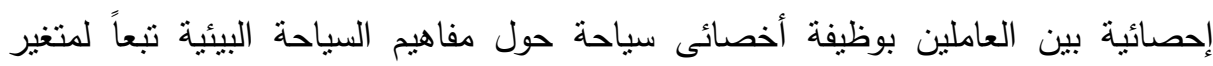
سنوات الخبرة". وذللك لصالح الفئة (11 سنة - 10 سنوات) كونها الفئة الأكثر خبرة وقدرة

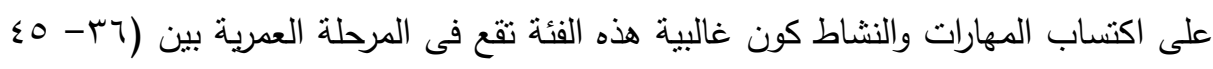
سنة) وهذا نتيجة طبيعية تقودنا الى وجود فروق ذات دلالة إحصائية بين العاملين بوظيفة

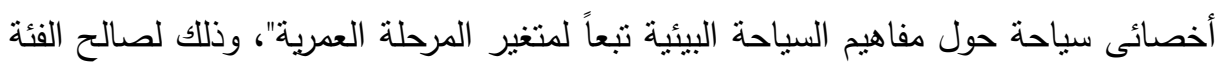

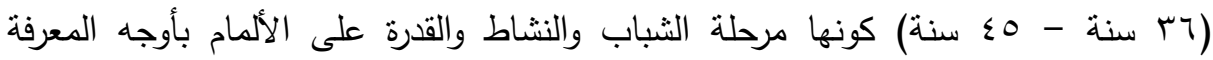
والمهارات المختلفة.

\section{تموسياهت الدراسما}

1. عمل دورات تدريبية متتوعة للتققيف بالمفاهيم السياحية البيئية ورفع مستوى الوعى البيئى لاى الأفراد وخاصة العاملين بوظيفة أخصائى سياحة والمؤسسات وعمل رحلات ميدانية

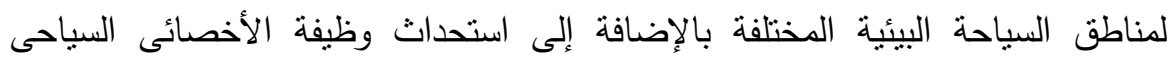
بالمدارس بمراحلها المختلفة لرفع الوعى السياحى البيئى منذ الصغر . 
r. إجراء مسابقات ثقافية سياحية للعاملين واسرهم والسكان المحليين هدفها التعريف بمفاهيم

السياحة البيئية.

r. إنتاج برامج سياحية بيئية على مستوى جيد من الفاعلية والأداء حتى يمكن ان تكون وسيلة دعائية وتثقيفية فى نفس الوقت تهدف إلى تتشيط الحركة السياحية البيئية وتتمية كفاءة العاملين فى مختلف مقاصد السياحة البيئية.

ع. الإهنمام بالخطط البحثية المدروسة التى تتتاول السياحة البيئية وضرورة تفعيل نتائجها

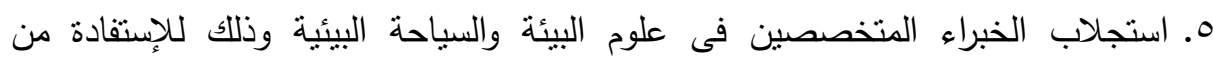
خبراتهم فى وضع برامج تعليمية وتدريبية تتتاول المفاهيم السياحية البيئية وتتفيذ خطط للتنمية السياحية البيئية بالإضافة إلى مواصلة الحوار مع المؤسسات الدولية والهيئات المتخصصة للترويج للمشروعات السياحية البيئية.

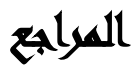

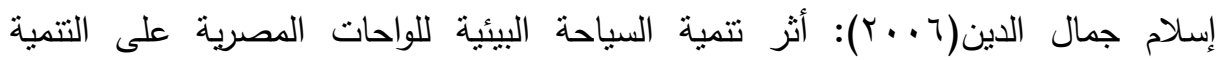

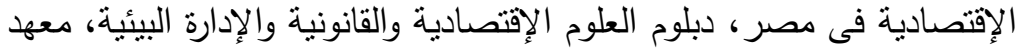

$$
\text { الدراسات والبحوث البيئية }
$$

اسماء فؤاد محمود(·(ب): فاعلية برنامج مقترح لتتمية المفاهيم والإتجاهات البيئية نحو

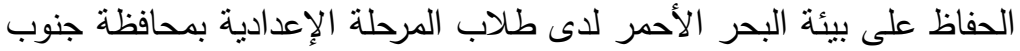

$$
\text { سيناء، معهد الدراسات والبحوث البيئية البهر }
$$

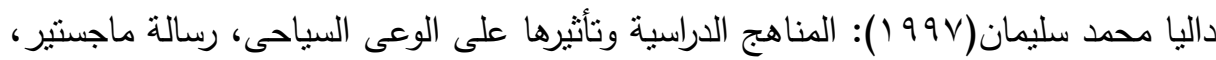

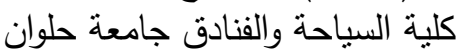

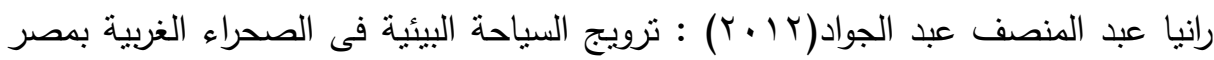
بالتطبيق على واحة سيوة، ماجستير، السياحة والفنادق، جامعة المنوفية

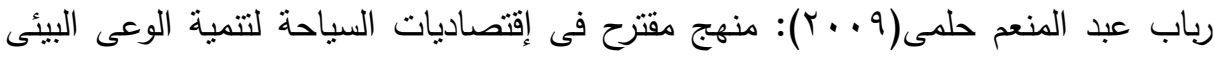

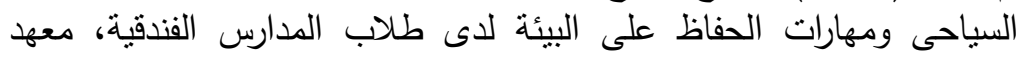

$$
\text { الدراسات والبحوث البيئية }
$$

$$
\text { صبرى عبد السميع( } 999 \text { ()): نظرية السياحة }
$$


أحمد إيراهيم شلبي وآخرون

عبد الرحمن عبد الفتاح واخرون( (.... r): السياحة البيئية

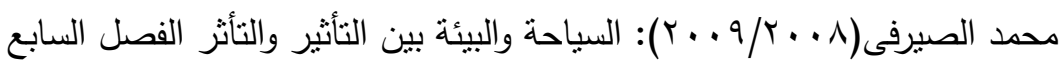

مريم محمود مصطفى(9 + . ץ): برنامج مقترح فى السياحة البيئية لتتمية المعارف والإتجاهات

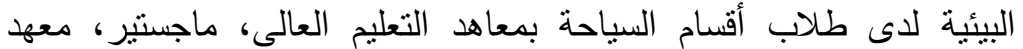

الدراسات والبحوث البيئية

منال شوقى عبد المعطى(· ( • ؟): دراسة فى مدخل علم السياحة نشوى عطا الله ب r • Y): السياحة المتواصلة والبيئة

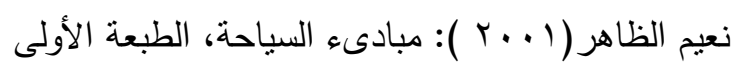

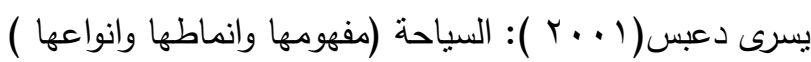

\title{
EVALUATION OF ENVIRONMENTAL TOURISM CONCEPTS AMONG SOCIETY VARIOUS CATEGORIES
}

Shalaby, A. I. ${ }^{(1)}$; Khair El-din, Azza, A. ${ }^{(2)}$ and Ibrahim, A. M. ${ }^{(3)}$

1) Faculty of Education, Ain Shams university 2) Faculty of Tourism and Hotels, Helwan University 3) Egypt Air Tourism ( KARNAK).

\begin{abstract}
This study is concerning some irresponsible practices by some employees in the company working as tourism specialist in tourism sector in egyptair company. the problem is supported by exploratory study has administatered on asample of workers as tourism professionals in the communiction center of egyptair company for tourism (karnak), indicating shortness in environmental concepts despite the difference in educational level, sex,years of experience .here emerges the need for this current study to evaluate the eco-tourism
\end{abstract}

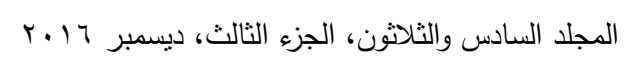


concepts as asignificant means for making positive practices towards the environment .

\section{The study was based on the descriptive analytical method:}

The study counts on the frequencies and percentages and Alfa Kronbak equation to calculate the stability of the tools

The study is implemented on a sample consisting of (300) items, using List (questionnaire) environmental tourism concepts reaching these results:

There are statistically significant differences at the 0.01 level of significance between the mean scores of male and female in the tourist environmental concepts scale, for the benefit of the average female scores.

There are statistically significant differences at the 0.01 level of significance between the mean scores of workers function of tourism specialist about the reality of eco-tourism concepts depending on the variable level of education, so as to favor PhDs.

There are statistically significant differences at the 0.01 level of significance between the mean scores of workers function of tourism specialist about the reality of eco-tourism concepts variable depending on years of experience, for the benefit of the category (11 years - 15 years).

There are statistically significant differences at the 0.01 level of significance between the mean scores of workers function of tourism specialist about the reality of eco-tourism concepts variable depending on age, for the benefit of the category (36 years - 45 years) . 